\title{
FASILITAS PENYEGARAN MENTAL
}

\author{
Marcella Felicia ${ }^{1)}$, Rudy Surya ${ }^{2)}$ \\ 1)Program Studi S1 Arsitektur, Fakultas Teknik, Universitas Tarumanagara, felis1373@icloud.com \\ 2) Program Studi S1 Arsitektur, Fakultas Teknik, Universitas Tarumanagara, rudys@ftuntar.ac.id
}

\begin{abstract}
Abstrak
Generasi milenial menghadapi banyak tantangan zaman. Tentu saja kemajuan teknologi dan bisnis dengan pesat membawa dampak positif namun juga dampak negatif bagi fisik dan mental. Dampak negatif mental yang terjadi adalah kecenderungan stress yang tinggi sehingga diperlukan sebuah fasilitas penyegaran, dimana arti kata 'penyegaran' sendiri adalah memberikan energi bagi fisik dan mental. Sehingga melihat dari kebutuhan program dan lokasi proyek, menghasilkan sebuah bangunan yang bergaya tropis dan berasitektur postmodern namun tidak meninggalkan cirikhas tradisional. Dengan atap yang juga berkemiringan curam dan memiliki banyak skylight menonjolkan cirikhas tropis dari bangunan. Fasad bangunan juga banyak mengandalkan material-material dasar kayu, beton dan kaca dengan warna-warna bernuansa hangat. Tipe dan perilaku juga berperan penting dengan cara saling mempengaruhi. Tipe sendiri merupakan sebuah konsep yang kemudian ada pada tipologi yaitu apakah tipologi bangunan yang akan terbentuk akan sama dengan sebelum-sebelumnya atau malah akan terbentuk tipologi baru yang akan membuat sebuah terobosan. Selain itu, proyek ini juga harus menggunakan metode penelitian pattern language yang dapat mempermudah proses desain yang rumit sehingga menghasilkan program ruang yang beragam.
\end{abstract}

Kata kunci: Mental; Milenial; Penyegaran; Tropis

\begin{abstract}
Millennials are facing many challenges in this era. Of course, the growth spurt of technology and business brings positive changes but also negatives for physical and mental. One of the negative sides is the higher rate of stress that causes people to demand a refreshment facility, where the word 'refreshment' itself means to give energy physically and mentally. Seeing from the programs needed and the project location, produce a building design that adapt tropical style and post-modern architecture without leaving the traditional value. With highly slanted roof and having many skylights protruding the tropical style of the building. The façade uses basic materials like woods, concrete, and glass with warm tone color. Type and behavior also take important roles by co-influencing each other. Type itself is a concept that occurs in typology which determines whether the new typology will be the same as it is before or will it be a new form of typology that start a breakthrough. Instead, this project must use pattern language method of design which makes complicated design more simplified, and in the end produces a final design that answers the Milenial problems.
\end{abstract}

Keywords: Mental; Millennial; Refreshment; Tropical

\section{PENDAHULUAN}

Bangsa Indonesia sudah dapat dikatakan berkembang pesat dengan berkembangnya teknologi yang praktis, instan dan tidak memerlukan mobilitas tinggi. Perkembangan tersebut memiliki dampak positif dan negatif. Dampak positifnya tentunya membuat kegiatan ekonomi di Indonesia meningkat dan transaksi perdagangan dalam maupun luar negeri makin memadai karena adanya sistem online dan jarak tempuh dari satu tempat yang jauh ke tempat lainnya menjadi singkat karena transportasi yang mumpuni juga berkembangnya media sosial untuk interaksi jarak jauh.

Ketatnya persaingan dalam dunia kerja juga membuat generasi milenial mempunyai banyak beban pikiran dan mudah stress karena padatnya kegiatan di tempat kerja sehingga membutuhkan perhatian khusus untuk kesehatan bukan hanya fisik namun juga mental. 
Penelitian terbaru dari Mental Health Foundation (MHF) yang tercantum dalam The Independent, sebuah surat kabar Inggris yang berbasis online edisi 14 Mei 2018, menemukan bahwa generasi milenial lebih stress dibandingkan kelompok usia lain yang lebih tua seperti generasi $X$.

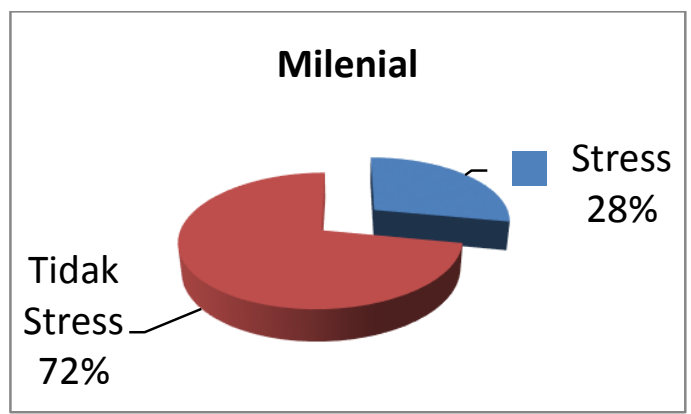

Gambar 1. Prosentase Stress Generasi X

Sumber: Penulis, 2019

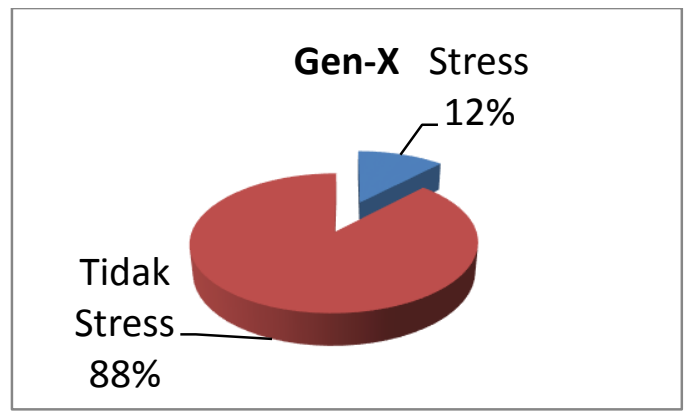

Gambar 2. Prosentase Stress Milenial Sumber: Penulis, 2019

Menurut Juru bicara MHF Richard Grange, tingginya stress pada generasi milenial disebabkan oleh tekanan yang lebih tinggi dari generasi yang sebelumnya. "Milenial cenderung memiliki kontrak kerja yang tidak aman, upah rendah dan beban kerja tinggi. Tekanan yang mereka hadapi sangat berbeda dibanding generasi sebelumnya," kata Grange kepada The Times yang dimuat dalam artikel Cable News Network Indonesia hari Senin, 4 Juni 2018. Berdasarkan laporan The Independent, studi ini merupakan lanjutan dari laporan MHF yang mengungkap sepertiga orang di Inggris pernah merasa ingin bunuh diri akibat stres yang tinggi. Dalam laporan itu MHF menyerukan perubahan sosial dalam menangani kesehatan mental bersamaan dengan cara memperlakukan pekerja karena kesehatan mental sama pentingnya dengan kesehatan fisik.

Maka, dalam hal ini berdasarkan seluruh faktor diatas, dicanangkan sebuah program yang memiliki efek untuk memulihkan kondisi mental seseorang yang sedang dalam kondisi stress atau membutuhkan pemulihan. Diharapkan proyek ini juga dapat mengatasi kebosanan yang terjadi dalam dunia kerja dan menjadi sebuah tempat rekreasi bagi pikiran dengan berbagai aktivitas yang membangun mental yang positif. Jika rumah sakit dapat mengobati penyakit dengan cara medis, maka proyek ini memulihkan dengan cara non-medis namun bertahap. Selain itu sebagai fasilitas tambahan, juga dirancang kegiatan-kegatan fisik untuk menjaga stamina agar tetap baik.

\section{KAJIAN LITERATUR}

\section{Generasi Milenial}

Dewasa ini, generasi millennials menjadi topik yang cukup hangat dikalangan masyarakat, mulai dari segi pendidikan, teknologi maupun moral dan budaya. Tapi sebenarnya, siapakah generasi milenial itu dan apakah masyarakat benar-benar mengerti akan sebutan itu? 
Milenials atau kadang juga disebut dengan generasi $\mathrm{Y}$ adalah sekelompok orang yang lahir setelah Generasi X. Millennials sendiri dianggap spesial karena generasi ini sangat berbeda dengan generasi sebelumnya, apalagi dalam hal yang berkaitan dengan teknologi. Generasi millennials memiliki ciri khas tersendiri yaitu, mereka lahir pada saat TV sudah berwarna, handphone juga internet sudah diperkenalkan. Sehingga generasi ini sangat mahir dalam teknologi.

Neil Howe dan William Strauss mendefinisikan Milenial sebagai generasi yang lahir pada tahun 1981-1996. Namun ada beberapa pendapat lainnya mengenai kaum Milenial.

1. Newsweek Magazine menuliskan bahwa milenial lahir pada tahun 1977-1994

2. Pada artikel lainnya, New York Times mematok milenial lahir pada tahun 1976-1990 dan 1978-1998

3. A Time Magazine memuat artikel yang menyatakan milenial lahir tahun $1980-2000$

\section{Penyegaran}

Berdasarkan KBBI, kata 'penyegaran' berasal dari kata dasar 'segar' yaang bisa memiliki beberapa arti yakni perasaan nyaman dan ringan. Dalam bahasa Inggris, kata ini diterjemahkan menjadi refreshment yaitu diperbaharui. Penyegaran tidak hanya berarti secara fisik, misal orang yang minum air saat haus akan merasa segar. Namun bisa juga diberikan kepada orang yang mentalnya sedang terganggu.

Sehingga yang dimaksud dalam penyegaran mental itu sendiri sebenarnya adalah kondisi mental yang sudah terisi dengan hal-hal yang tiak baik kembali mengalami pembaruan dengan hal-hal yang positif sehingga kembali ke kondisi mental yang sehat.

\section{METODE}

Pada buku 'A Pattern Language' oleh Christopher Alexander, ada sebuah bahasa pola yang telah digunakan sejak lama yang dapat dipakai sebagai panduan dalam merancang apa saja. Elemen dalam bahasa ini berupa pola. Tiap pola mendeskripsikan isu yang muncul berulang-ulang pada lingkungan manusia lalu kemudia menentukan pemecahan dari inti masalah yang solusinya kemudian bisa digunakan berulang-ulang dengan hasil dan pendekatan yang berbeda-beda.

Pola yang terjadi saling berhubungan dan pola yang kecil melengkapi pola yang lebih besar lalu pola itu terhubung dan melengkapi pola yang lebih besar lagi dan seterusnya sehingga pola solusi dapat dikombinasikan sesuai kebutuhan tanpa merubah esensi dasarnya. Contohnya : Dalam membuat daerah hijau yang mudak diakses, Hal ini merupakan sesuatu yang fundamental dimana di dalam membuat sesuatu, ia tidak dapat berdiri sendiri melainkan harus juga memperbaiki lingkungan sekitarnya sehingga menjadi sesuatu yang utuh dan koheren.

Karena proyek yang akan dilakukan merupakan sebuah proyek yang menyangkut mental manusia sedangkan metode Pattern Language membahas solusi desain yang kompleks menggunakan cara yang manusiawi dengan pola pikir yang simpel. Karena mental manusia adalah permasalahan yang kompleks maka memerlukan solusi desain dengan kompleksitas tinggi juga namun dapat dicapai dengan simpel dan efektif maka dirasa Pattern Language adalah metode perancangan yang tepat.

\section{DISKUSI DAN HASIL}

Berada jauh dari pusat kota dan dekat dengan Laut menjadikan lokasi Pantai Indah Kapuk, Jakarta Utara, tepat untuk mendirikan Fasilitas Penyegaran Mental ini. Karena Pantai Indah Kapuk merupakan zona bangunan rendah dan kawasan hutan lindung menjadi faktor utama pendukung lokasi proyek. Tapak persisnya berada di sebelah Rumah Sakit Pantai Indah Kapuk. 


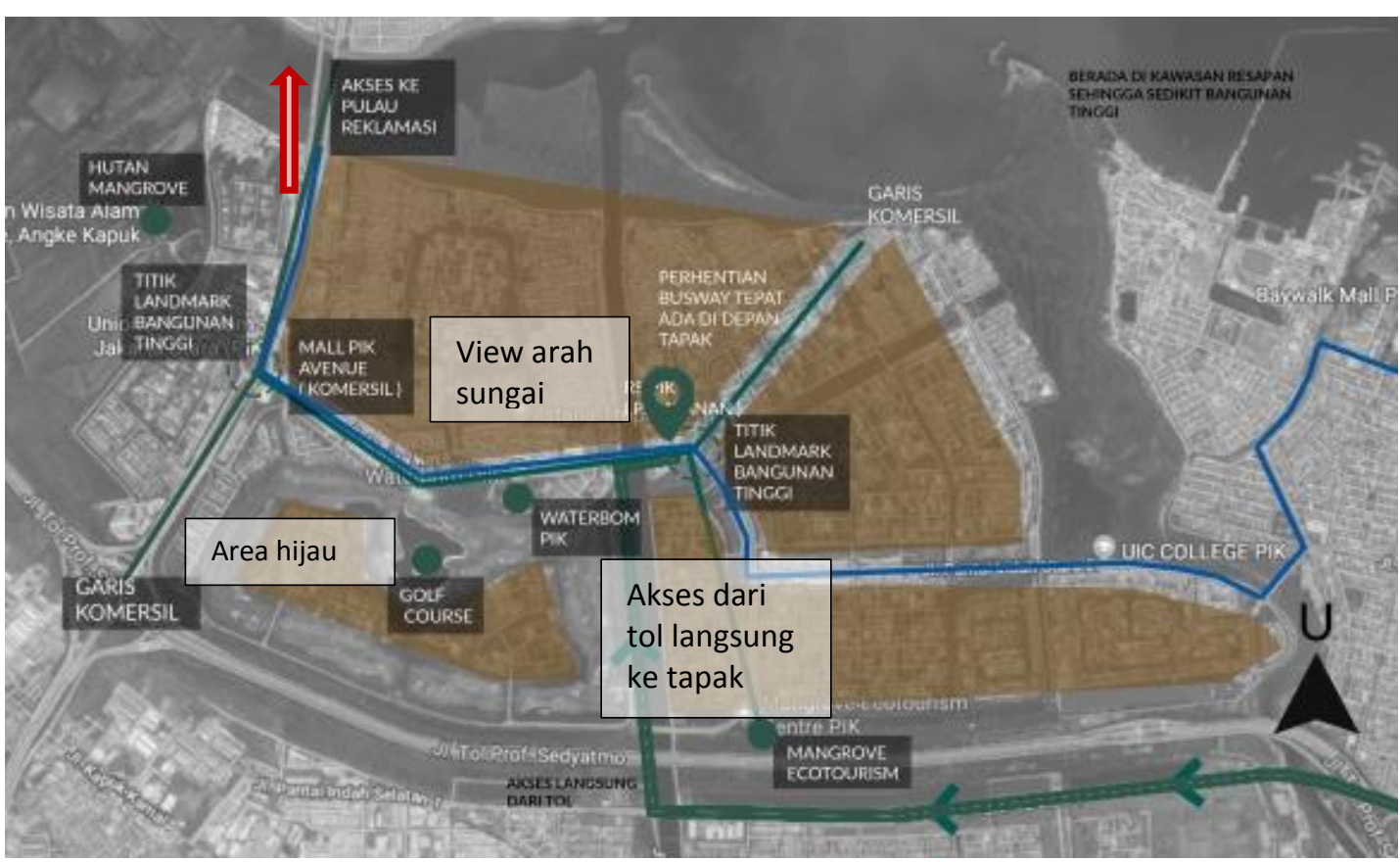

Gambar 3. Analisis Makro Tapak

Sumber: Penulis, 2019

Area hijau dan sungai yang terletak di sebelah Barat menjadikan terbentuknya zonasi tapak yakni area penyembuhan yang berada di Barat dan jauh dari jalan utama dengan area penyegaran yang dapat langsung diakses dari jalan utama.
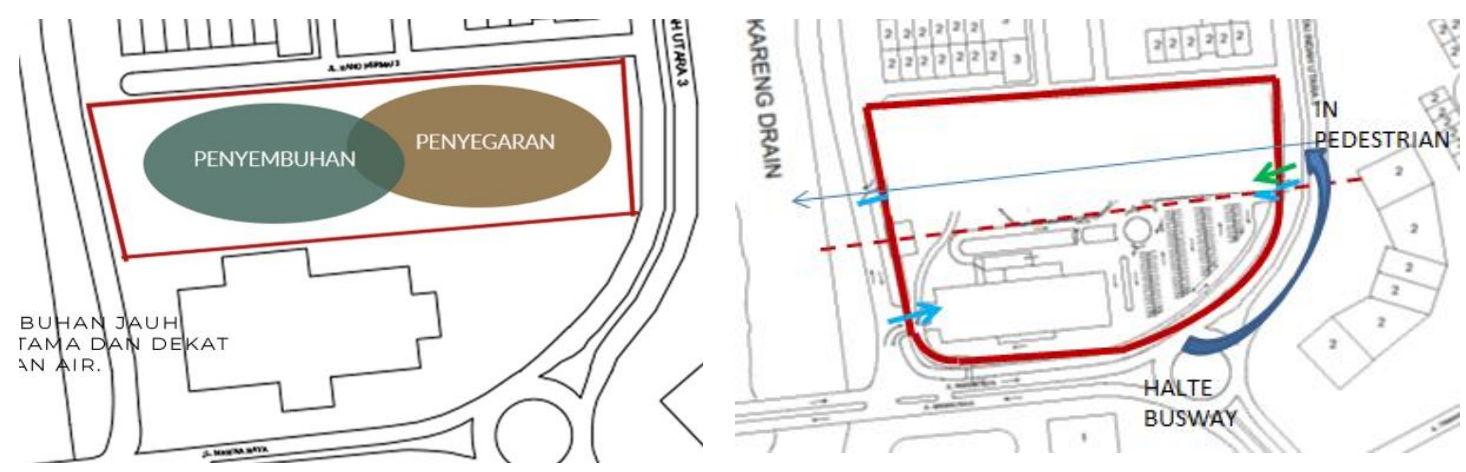

Gambar 4. Analisis Mikro Tapak Sumber: Penulis, 2019

Akses menuju tapak dibuat dekat dengan bundaran yang menjadi titik tangkap proyek. Sedangkan akses sekunder dan darurat dibuat di sebelah Barat tapak. 


\section{Dari analisis zonasi dan akses tapak membentuk sebuah proses gubahan massa.}
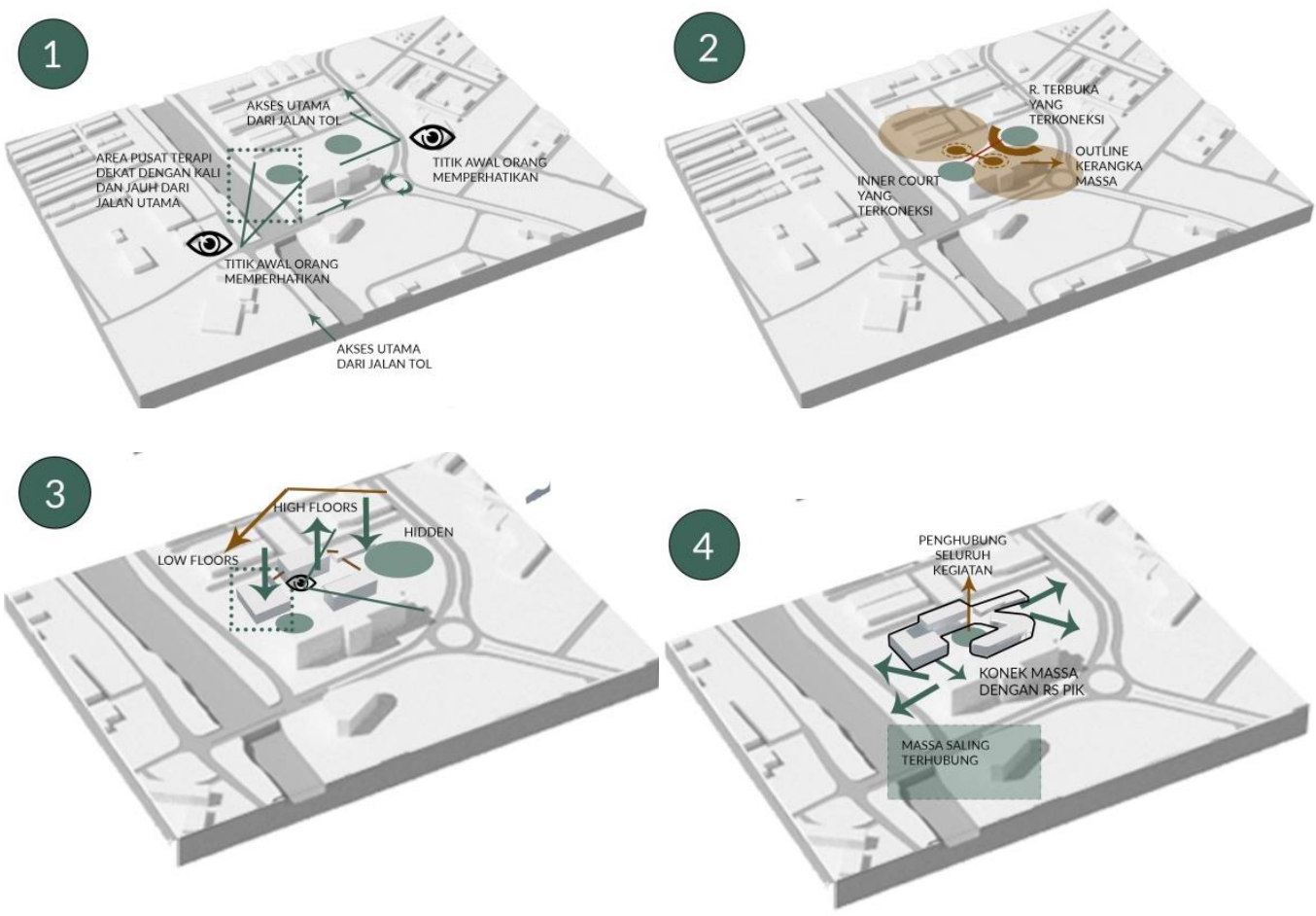

Gambar 5. Proses Gubahan Massa Sumber: Penulis, 2019

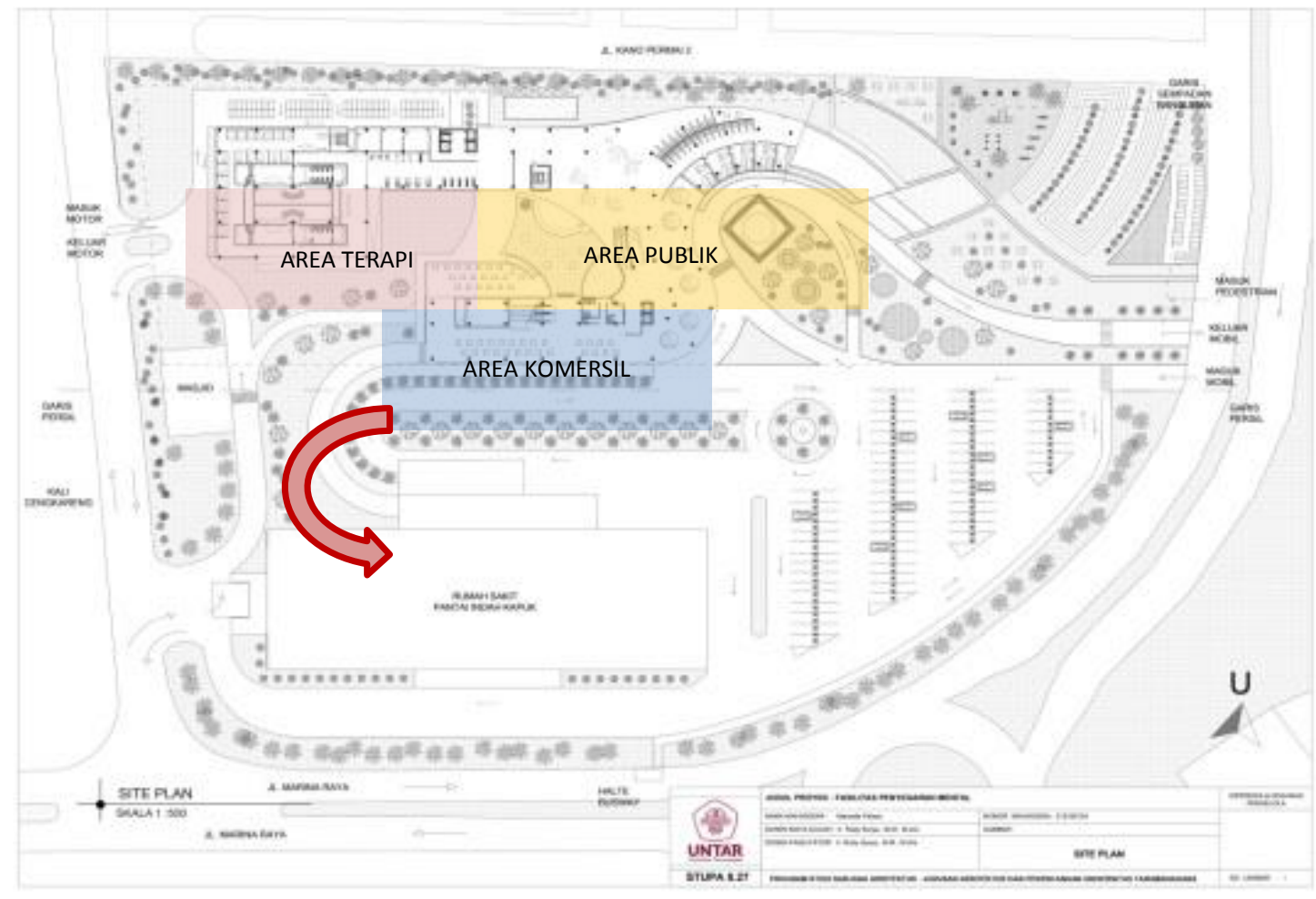

Gambar 6. Site Plan

Sumber: Penulis, 2019 
Proyek ini dibagi menjadi 3 zona utama yaitu zona komersil, zona publik, dan zona terapi. Zona publik pada bagian depan sebagai penyambut untuk pengunjung. Setelah itu terbagi menjadi 2 antara pengunjung ingin mengakses area terapi atau area komersil. Area komersil terhubung dengan Rumah Sakit dengan jalan pedestrian yang berkanopi.

Pada buku 'Knowledge-Based Systems in Biomedicine and Computational Life Science' oleh Sadaka Sato, dilakukan survey terhadap terapi yang efektif untuk mengatasi stress dan hasil dari penelitian yang dilakukan terapi menggunakan panca indera sangat efektif. Sehingga mengambil 3 dari 5 panca indera yang ada, terapi yang ada terbagi menjadi berikut:

- Physical Contact Theraphy

$>$ Water Theraphy

Studi yang dilakukan pada Biopsychologic Effect on Warm Water Immersion yaitu menggunakan elemen air untuk berendam menunjukkan bahwa selain bermanfaat untuk fisik ternyata juga mengurangi kadar stress. Ruang yang ada terbagi menjadi :

\section{Water Immersion}

Dengan ilustrasi ruang sebagai berikut:

2. Hydrojet Bath

Terapi dengan tekanan air

3. Cold Shower

Terapi dengan air dingin

\section{$>$ Relaxation Theraphy}

1. Sauna

2. Spa

3. Gym

- Visual Therapy

Termasuk dalam ranah seni, University of Westminster meriset bahwa memandang sebuah 'visual art' dapat menjadi medium untuk merasakan suasana yang rileks dimana orang-orang yang telah memandang karya seni dalam waktu tertentu memiliki level hormon kortisol yang lebih rendah dibanding yang tidak. Hormon kortisol sendiri adalah hormon yang berperan pada perasaan stress. Berikut ilustrasi ruang visual yang ada pada proyek:

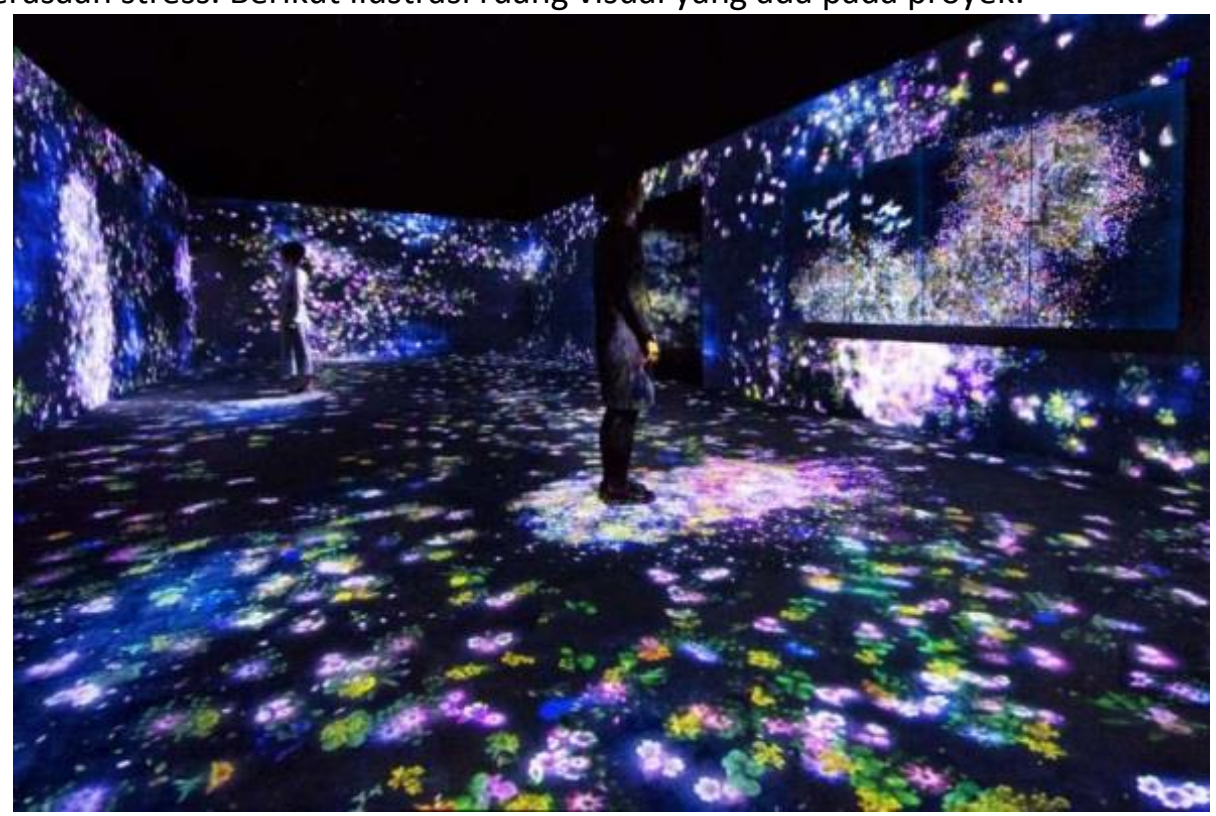

Gambar 7. Ruang Visual Theraphy

Sumber: Penulis, 2019 


\section{- Audio Theraphy}

$>$ Music Theraphy

Pada jurnal yang ditulis oleh Myriam V. Thoma mengenai efek musik dan audio ke dalam tingkat stress seseorang, membuktikan bahwa memperdengarkan musik dengan jenis tertentu dapat mengurangi tingkat stress seseorang walaupun tidak semuanya.

$>$ Nature Biofeedback Theraphy

Pada jurnal yang berbeda namun pengarang yang sama, efek serupa juga dihasilkan saat mendengarkan suara alam termasuk air. Ilustrasi ruang yang dimaksud adalah sebagai berikut:

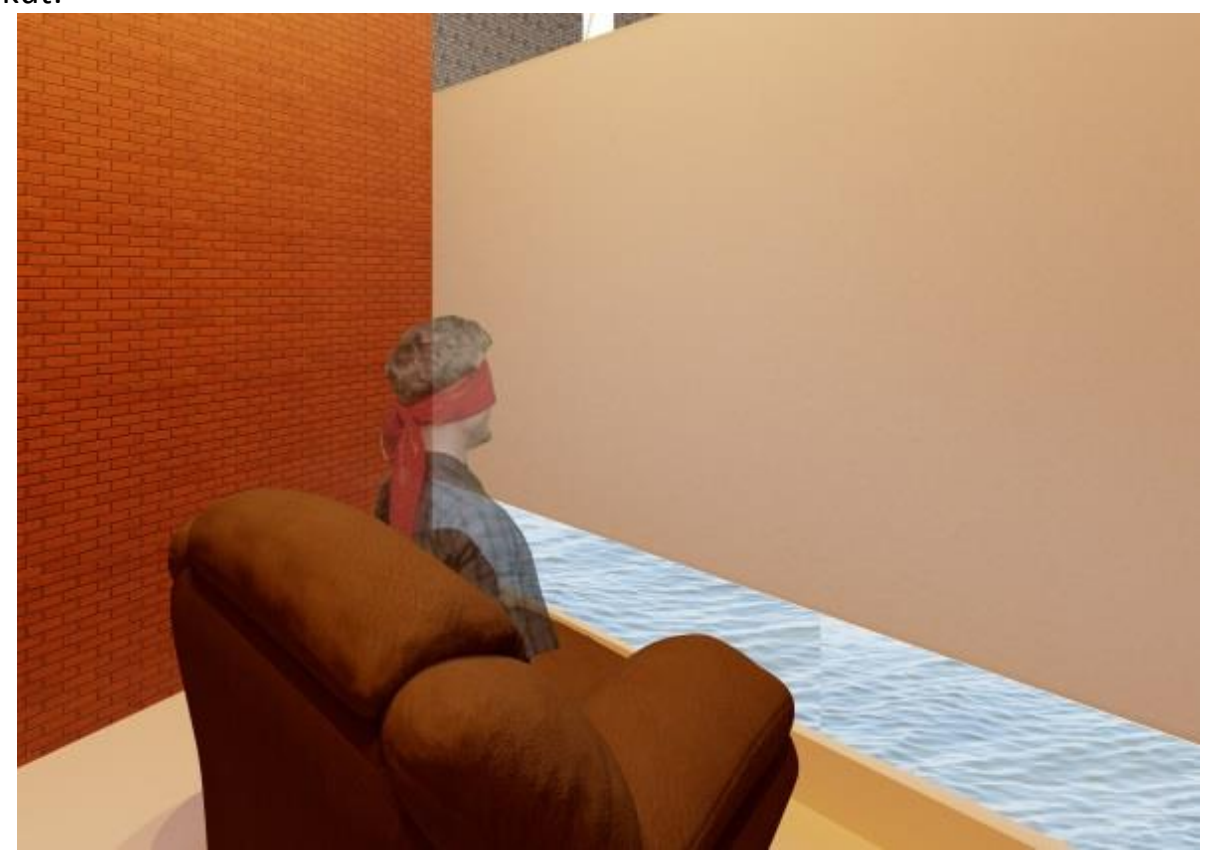

Gambar 8. Ruang Nature Biofeedback Theraphy Sumber: Penulis, 2019

Sedangkan fasilitas pendukung lainnya yaitu fasilitas untuk rawat jangka singkat yang suasananya dibuat menyerupai hotel sehingga pasien tidak merasa sedang dalam tahap pengobatan. Terdapat juga café yang dapat menjadi 'sharing facility' dengan rumah sakit sehingga dapat dinikmati banyak orang.

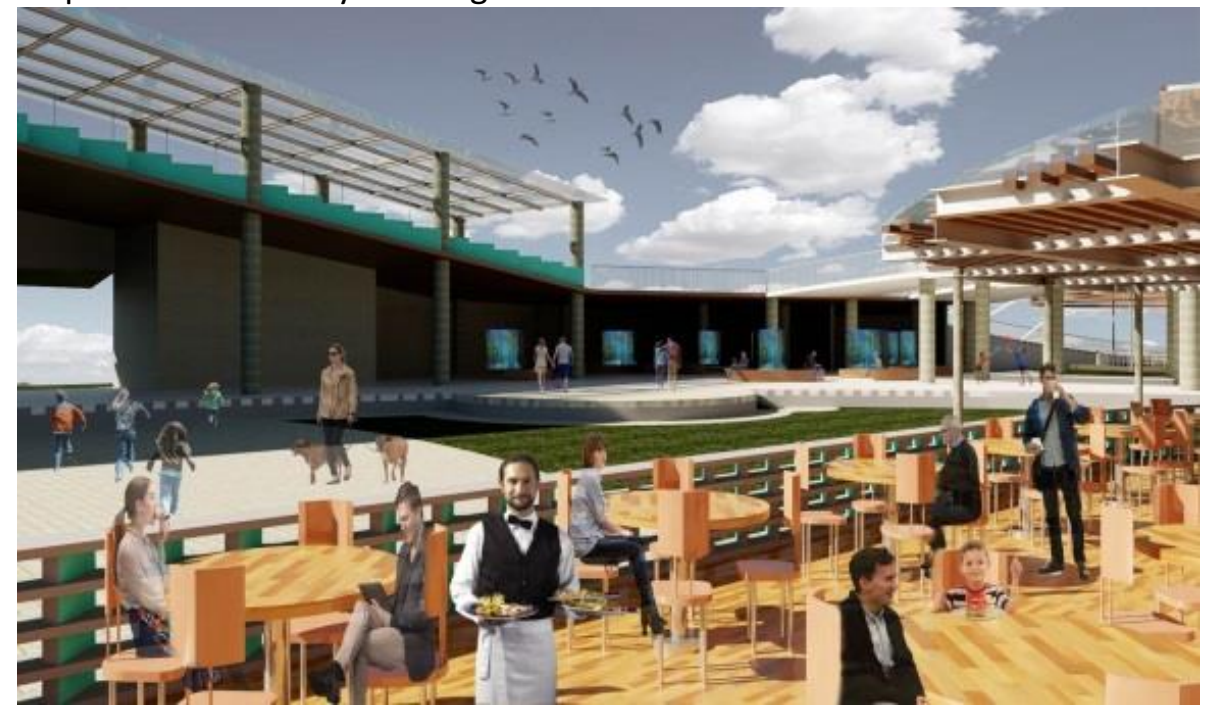

Gambar 9. Ilustrasi Café dan Suasana

Sumber: Penulis, 2019 
Konsep umum yang digunakan adalah suasana rilek dengan alunan suara alam seperti di Bali dengan paduan sentuhan modern tanpa menghilangkan ciri tradisional.

Material yang digunakan juga harus mendukung suasana yang tercipta namun juga cocok untuk daerah yang dekat dengan laut sehingga tidak lapuk atau lembab dengan tone warna agak hangat. Pada fasad diberi aksen warna biru untuk menjadikan highlight dari proyek ini juga selaras dengan rumah sakit yang juga mempuyai beberapa aksen biru. Pemberian warna biru juga karena menurut survey dari seluruh warna yang ada warna biru muda memberikan efek terapi dan ketenangan.

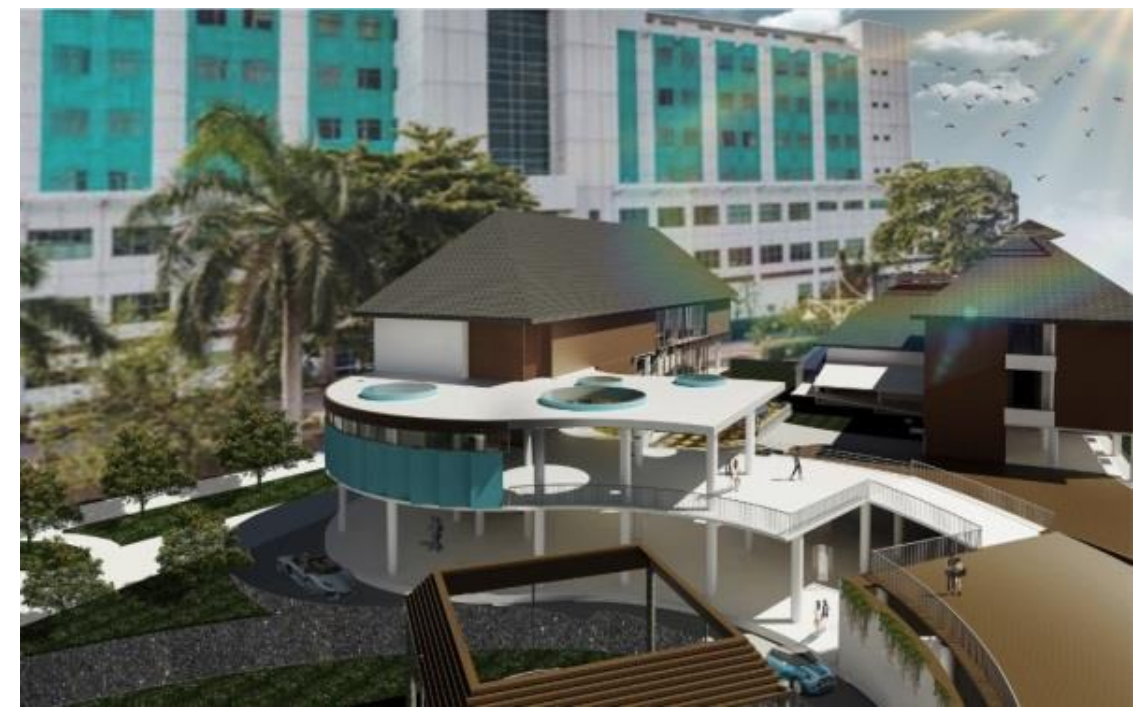

Gambar 10. Perspektif Mata Burung

Sumber: Penulis, 2019

\section{KESIMPULAN DAN SARAN}

Fasilitas Penyegaran Mental berperan sebagai wadah pemulihan dan pengisian kembali energi bagi para penderita stress dengan cara terapi non-medis dan visual yang baik serta peran serta alam.

Desain yang diusulkan menggunakan banyak open space dengan area olahraga outdoor dan area publik yang banyak mengandung elemen air untuk keperluan terapi audio dan visual. Tapak juga terbagi menjadi 2 area yaitu penyembuhan dan penyegaran dengan elemen terapi berada di area penyembuhan, seperti : terapi, air, terapi audio dan terapi visual. Sedangkan diluar itu termasuk kedalam area penyegaran.

Diharapkan proyek ini dapat menjadi sebuah pusat relaksasi bagi warga Jakarta yang setiap harinya menghadapi rutinitas dan keseharian yang padat. Kedepannya juga proyek ini bisa dikembangkan lagi bukan hanya difokuskan secara mental namun juga secara fisik dengan ditambahkan fasilitas-fasilitas kebugaran dan area yang lebih luas. Bisa juga bergabung menjadi sebuah kesatuan dengan Rumah Sakit PIK sehingga pengobatan yang disediakan juga bisa secara medis.

\section{REFERENSI}

Alexander, C. A Timeless Way of Building. (1979). $1^{\text {st }}$ ed. New York : Oxford University Press. Alexander, C. dkk.. (1977). A Pattern Language. $1^{\text {st }}$ ed. New York : Oxford University Press. Howe, N. Strauss, W. (2000). Millennials Rising: The Next Great Generation. $3^{\text {rd }}$ ed. United Kingdom : Vintage.

Jacoby, S. (2015). Type versus Typology Introduction. The Journal of Architecture, 20, 931. 
Juniman, P. T. (2018, 4 Juni). Studi: Milenial Lebih Stres di Kantor Dibanding Usia Lain. Dikutip 20 Januari 2019 dari CNN Indonesia : https://www.cnnindonesia.com/gaya-hidup/studimilenial-lebih-stres-di-kantor-dibanding-usia-lain

Putri D., W. (2019, 19 Maret). Ada Perubahan Cara Kerja Karyawan di Era Transformasi Digital. Dikutip 18 Maret 2019 dari Republika : https://www.republika.co.id/berita/gayahidup/trend/17/04/11/oo8p99359-ada-perubahan-cara-kerja-karyawan-di-era-transformasidigital

Rossi, A. (1982). The Architecture of the City. New York: The MIT Press.

Rudi, A. (2016, 23 Februari). Inilah Kawasan yang Telah Berubah dari RTH Jadi Perumahan dan Area Perdagangan. Dikutip 7 Maret 2019 dari Kompas.com : https://megapolitan.kompas.com/read/2016/02/23/15130671/Inilah.Kawasan.yang.Telah.B erubah.dari.RTH.Jadi.Perumahan.dan.Area.Perdagangan.

Sato, S. (2013). Miao, Tiejun. Oyama-Higa, Mayumi. Knowledge-Based Systems in Biomedicine and Computational Life Science. $2^{\text {nd }}$ ed. New York: Springer Heidelberg.

Stack, L. (2018). Are You 21 to 37? You Might Be a Millennial. New York : The New York Times. (16 Mei 2019), pg. 3.

Thoma, M.V., Mewes, R \& Nater, U.M. (2018). Preliminary evidence: the stress-reducing effect of listening to water sounds depends on somatic complaints. Medicine (Baltimore), 97(8), 1-5.

Thoma, M.V., La Marca, R., Bronnimann, R., Finkel,L., Ehlert, U., \& Nater, U.M. (2013). The Effect of Music on the Human Stress Response. Plos One, 8(8).

Vitruvius. (1999). Ten Books on Architecture. New York: Cambridge University Press.

Wangsa W., S. (2017, 10 Februari). Studi: Generasi Milenium Paling Stres di Tempat Kerja. Dikutip

$$
\text { Maret }
$$

2019

dari Kompas.com https://lifestyle.kompas.com/read/2017/02/10/170400720/studi.generasi.milenium.paling.s tres.di.tempat.kerja 
